\title{
P-FUTURES: Towards urban food $\&$ water security through collaborative design and impact
}

\author{
Author Name and Affiliations: \\ David M. Iwaniec ${ }^{1 *}$, Geneviève S. Metson ${ }^{2{ }^{*}}$, Dana Cordell ${ }^{2}$ \\ ${ }^{1}$ Julie Ann Wrigley Global Institute of Sustainability, Arizona State University, Tempe, \\ AZ 85287-5402, USA \\ ${ }^{2}$ Institute for Sustainable Futures, University of Technology Sydney, PO Box 123, \\ Broadway, NSW 2007, Australia \\ *Co-first authors and corresponding authors: diwaniec@asu.edu, \\ genevieve.metson@wsu.edu \\ ${ }^{+}$Current address: \\ National Research Council, National Academies of Science, Washington, D.C. USA \\ 20418 \\ Washington State University, School of the Environment, Vancouver, WA USA 98686
}

\begin{abstract}
Phosphorus is essential to food production, but current management practices fail to ensure equitable access to farmers globally and often results in polluted waterways. There is a lack of local and global governance mechanisims to ensure phosphorus is sustainably managed. The P-FUTURES research initiative aims to address this gap by working with stakeholders to explore visions and pathways of social transformation toward food and water security. In the seed phase of the project, academic, civil, industry, and municipal stakeholders interacted as partners in Blantyre (Malawi), Hanoi (Vietnam), Sydney (Australia), and Phoenix (USA) to collaboratively develop a full proposal and build capacity for transformational change. The article offers guidance on the opportunities and challenges of co-developing a research approach and proposal in a transdisciplinary, international setting.
\end{abstract}

\section{The Phosphorus Challenge}

Human consumption of phosphorus for food production and industrial uses has increased over fivefold since the 1960's [1], making human activities the driving force of phosphorus flows on the planet [2-6]. Sustainable phosphorus management has been recently emphasized as an essential component to meet UN global food security and water quality objectives [7]. Without access to phosphorus, farmers and nations will not be able to produce sufficient food, yet there are no effective governance mechanisms in place to ensure long-term access to the resource or to stimulate sustainable phosphorus 
practices $[8,9]$. Remaining reserves are non-renewable, unevenly distributed, and becoming increasingly scarce and expensive; nearly one billion of the world's poorest farmers are unable to access fertilizer markets [9]. At the same time, losses of phosphorus along the food chain, from runoff and soil erosion from fields, all the way to human and animal excreta and urban food waste, contribute to widespread water pollution [10]. Phosphorus losses to waterways lead to eutrophication [11,12], which in turn can cause toxic algal and cyanobacterial blooms (affecting drinking water supply) and hypoxic zones [13-16].

Cities can be catalysts for larger scale change through their strong political and economic influence and are crucial centers for decision-making and innovation (as seen with global change [17], and specifically climate change [18]). As such, urban areas could be key agents in responding to the global phosphorus challenge because cities are 'phosphorus hotspots', i.e. cities concentrate people, and by doing so concentrate both the demand for food and the generation of phosphorus-rich organic waste [19-21]. For example, cities are being reimagined as closed loop systems where phosphorus in waste streams become resource opportunities for urban and peri-urban agriculture [22-24]. Urban environments therefore represent both the scarcity and pollution sides of the phosphorus challenge and potential solutions.

Local interventions to address scarcity and pollution aspects of the phosphorus challenge have often had unintended consequences. For example, fertilizer subsidies in India, to increase access to farmers, unintentionally created a black-market for fertilizers in Nepal-distorting local markets [25,26]. In the USA, Lake Erie initially saw decreases in harmful algal blooms with the application of a suite of changes in local farming practices and increased treatment of urban wastewater. However, unintended interactions between national energy policies, the selection of "best management practices" such as no-till agriculture, and climate change effects have resulted in the re-emergence of the algal blooms [27]. We use these examples to demonstrate that addressing individual causes of local scarcity or pollution separately may not be sufficient to address phosphorus sustainability challenges. It is not enough to trust that uncoordinated, incremental knowledge and actions will be sufficient to solve these challenges.

Food and water security will need to entail transformative outcomes in phosphorus sustainability, including explicit consideration of global and local resource governance, human well-being and livelihoods, and account for the persistent and growing challenges of inequity, urbanization, and climate change [28,29].

\section{Transdisciplinary Gap to Move Towards Phosphorus Social Transformations}

Scientists have made great strides in understanding the biophysical and technical dimensions of the phosphorus challenge (e.g., [30-32]), but these strides have not resulted in the large-scale transformations needed to ensure global (or even local) food security and clean water. There is an increasing awareness that this inaction is related to gaps in knowledge around the social dimensions of the phosphorus challenge and how this knowledge is integrated into decision-making [20,33]. In particular, different 

different ways [9], and therefore governance strategies must be locally adapted.

Substance flow analyses has been the dominant tool to understand the movement and storage of phosphorus and to help decision makers improve phosphorus management [1920]. However such studies have rarely resulted in significant changes, in part because they lack explicit inclusion of the unique context-specific environmental, governance, and institutional drivers of phosphorus access and use [9,20]. For example, Kalmykova et al. [34] and Gumbo [35] note that the cultural acceptance of waste reuse could be a barrier to increasing phosphorus recycling, however was not within the scope of their quantitative studies. The cross-scalar nature of the phosphorus challenge from global to local [9] and past to future is also a key barrier to transformation [23]. Infrastructure lockins and governance legacies constrain the types of solutions that are available to cities [36-38]. Similarly, MacDonald et al. [39] demonstrate how global trade and national farming and energy policies affect local farming phosphorus flows in the USA and are a socio-political barrier to change. In fact, phosphorus management is linked to both national and urban sustainability and resilience priorities (e.g., food, water, energy, poverty alleviation, and ecosystem integrity). However, these linkages are often not made explicit [20,40-42].

In order to address these knowledge gaps and to create "on the ground" change, there is a need to integrate local stakeholder knowledges specifically through co-production processes [43-45]. Moving beyond engineering technical solutions toward co-developing social-ecological-technological transformations that affect how we use and govern this resource are necessary $[9,20]$.

\section{P-FUTURES Seed Phase Approach}

P-FUTURES is a cross-city initiative designed to address phosphorus security challenges and opportunities, funded by the ISSC as a contribution to the Future Earth Transformations to Sustainability programme. P-FUTURES aims to co-create the foundations for transformative change on a trajectory toward food security and water resource integrity. The seed phase (6 months) was designed to create relationships among stakeholders and researchers across cities and design a research approach to social transformations that would be viable for a 3 year project. This phase focused on four cities: Hanoi (Vietnam), Blantyre (Malawi), Sydney (Australia), and Phoenix (USA). The existence of sufficient available phosphorus information and existing research contacts, keen to participate, influenced city selection. We selected these cities to span a wide range of socio-economic and biophysical conditions in order to explore a more comprehensive range of governance, institutional, and social arrangements, as well as technological strategies than can be used in creating sustainable phosphorus pathways.

In contrast to uncoordinated, incremental knowledge and actions, deliberate social visions and implementation pathways for sustainable transformations are needed. This requires reframing research-practice approaches for how and who addresses these challenges [46], as well as defining clear intended outcomes (knowledge, situation, and mutual-learning) 
from the onset of the transdisciplinary research approach [45]. In line with Midgley [47] and other soft systems theorists and practitioners, the P-FUTURES team aims for an ethical commitment to creating change through a participatory and reflexive systemic inquiry. As such the seed phase research approach focused on building capacity towards deliberate transformative social changes that: 1) enhance equity, well-being, and livelihood, 2) avoid environmental degradation, and 3) avoid unintended consequences $[46,48]$. We draw from transdisciplinary research in sustainability science $[43,49]$, adaptive capacity and learning [50-51], future desirable pathways [52-54], and transition management [55-56]. The co-production framework [43-45] was to: 1) share and understand who, what, and how relevant actors, system features, and existing priorities interact with phosphorus, and to identify relationships and common goals, 2) understand (and to an extent experience) each city's specific vulnerability to global, regional, and local aspects of the phosphorus challenge, 3 ) develop participatory visions and pathways for sustainable food and water systems, and 4) assess the participants' envisioned implementation strategies. The seed phase was used to carry-out experiential learning and workshop activities to build this capacity among stakeholders and researchers in order to refine and deepen the co-production approach put forth in the full proposal.

$<$ insert figure $1>$

Experiential learning included stakeholder visits to urban and peri-urban farms and gardens, landfills and composting facilities, wastewater treatment plants, chemical fertilizer plants, food distribution centers, in addition to diverse socio-economic neighborhoods, and managed and unmanaged natural areas. Full-day interactive workshops engaged over 95 stakeholders (including researchers) across the four cities. We conducted stakeholder mapping to ensure an appropriate diversity of sectors and interests were reflected (Box 1; for detailed stakeholder list see http://p-futurescities.net). Core workshop activities included:

1) Mapping the current situation and existing goals: Each stakeholder identified their current sector/institution priorities and drivers, and collaboratively integrated these through facilitated systems mapping activities to explore interrelationships, conflicts, trade-offs, and synergies (Figure 2).

2) Vulnerability assessments: Using the systems maps of the local, current situation developed in (1), participants co-explored how global phosphorus vulnerabilities $[9,33,57]$ affect and propagate through their city systems through 'what if' probing questions [51] (e.g., What would the effect of a 500\% increase in phosphorus fertilizer prices be on the city?).

3) Visions and pathways: International examples of sustainable phosphorus management strategies stimulated cross-city comparison and fertilization of ideas to initialize the visioning process. Participants identified sector specific and integrated future goals and explored relationships, trade-offs, and synergies through the systems maps [44,53-54].

4) Assess implementation strategies: After a discussion on social transformational 
change, participants appraised their strategies and goals then revised them to ensure that they encompassed: principles of equity, justice, and sustainability; significant changes with big implications; real lasting change; and multiple scales and sectors [51]. Followed by a plenary synthesis, the participants identificated next steps to collaboratively develop the full proposal.

$<$ insert figure $2>$

\section{Challenges and Opportunities of a Collaborative Approach}

The overarching goal of the seed phase of the P-FUTURES initiative was to build capacity for transformational change. It was challenging to balance different disciplinary approaches to transformation, link differing stakeholder priorities and needs, as well as minimize trade-offs between the need to be multi-scalar and site-specific with immediate relevance. For each of these challenges we describe how it was experienced and addressed in the seed phase and then identify opportunities to improve co-production in the full proposal.

Early in the process, cross-city research team discussions about their desired outcomes for the project revealed the need to build capacity to think across knowledge domains and bridge divergent perspectives on what qualified as a transformative outcome. For example, some stakeholder and research partners were predominantly interested in seeking out infrastructure and technological solutions and pilot demonstration projects. Part of these disciplinary suggestions stemmed from a desire to quickly address immediate, local needs related to food security and water quality before considering the long-term implications of these strategies. Throughout the process we faced the need to carefully communicate constraints (and opportunities) in the type and scope of implementation initiatives that the project could support. For example, being careful about setting project expectations given the initial scope, funding, and time constraints of the seed grant. Not surprisingly, project goals and funding was an especially challenging conversation, in that continued funding was both uncertain and short-term, whereas social transformations are a long-term endeavor. After an initial struggle in our first workshop, in subsequent workshops we included explicit discussions on the scope of implementation initiatives as well as asked participants to appraise how transformative their strategies and goals were.

In order to create a salient and relevant proposal, we aimed to link existing priorities and goals to each other, and to holistically address the phosphorus challenge. Stakeholders (including researchers) first worked individually within their sphere of knowledge and elicited their own local priorities and challenges. They then combined their local understanding with new knowledge about global phosphorus challenges to integrate new networks and knowledge relevant to their specific issues. Many of these linkages were new to stakeholders, increasing their understanding of both the challenges and opportunities their city will face in the future. The systems approach to this newly created knowledge also allowed stakeholders to identify missing relationships that need to be included in the next phase of the project. For example, in Blantyre new relationships 
between water quality and energy production were uncovered during systems mapping of urban priorities that had not been previously considered. This informed the development of the full proposal by identifying previously overlooked stakeholders.

There was a tension between the need to accommodate co-production and site-specific stakeholder needs and the desire to design research comparable across cities. There was an emphasis on building capacity for cross-city learning, in that the participatory settings included the involvement of international partners, presentation of phosphorus sustainability issues and solutions from other partner cities, and post-workshop distribution of summaries and updates through the project website. However, overall workshop design prioritized co-production processes and local needs over cross-city learning. One important reason for focusing workshop and engagement design around local context was to accomodate for each city's vastly different levels of experience with sustainability, formal planning, and natural resource management. For example in contrast to Blantyre, Phoenix already had experience with scenario approaches in municipal planning. The project has yet to allow international partners to deeply learn from each other but the next phase of the project has been designed to foster more crosscity learning. For example, researchers from all partner cities will attend stakeholder workshops abroad, annual in person meetings with the full reserach team will allow for more discussion, and a stakeholder advisory board with rotating membership will provide a space for international stakeholders to communicate directly.

\section{Conclusions}

Food and water security, urbanization, and phosphorus sustainability are pressing, interlinked issues that must be explored. The seed grant phase of P-FUTURES focused on eliciting preliminary knowledge, scoping the larger project and most importantly, collaboratively building the foundations of a knowledge action network: trust and motivation to develop a deep shared understanding of appropriate transdisciplinary approaches. Developing shared expectations with participants was an especially crucial process for transformational research-practice and resulted in the exploration of key governance and social levers that address immediate solutions and long-term sustainability pathways. Moving forward P-FUTURES will continue to commit to the inclusive involvement of stakeholders, frame the engagement process as a collaboration among full partners, and co-develop the capacity to envision and realize transformational changes.

\section{Acknowledgements}

We would like to thank the 95 partners across the four countries who participated in PFUTURES (see: http://www.p-futurescities.net/the-p-futures-project/) including the research partners at the Centre for Water, Sanitation, Health \& Appropriate Technology Development (University of Malawi - The Polytechnic), Institute for Environmental Science \& Engineering (National University of Civil Engineering, Vietnam), Julie Ann Wrigley Global Institute for Sustainability (Arizona State University, USA), and the Institute for Sustainable Futures (University of Technology Sydney, Australia). We thank the International Social Science Council, Future Earth Transformations to Sustainability 
programme (Project ID. T2S_PP_136), the US National Science Foundation Central Arizona Project Long-Term Ecological Research (Grant No. 1026865) for their financial support, and US National Science Foundation Urban Sustainability Research Coordination Network (Grant No. 1140070).

\title{
List of Figures:
}

Figure 1. P-FUTURES collaborative project: the phosphorus challenges, P-FUTURES approach, and planned outcomes. Yellow arrows indicate the workflow of the seed phase of the project. Green arrows indicate the continuation of the P-FUTURES project and intended impacts.

Figure 2. Blantyre workshop: Stakeholders engage with each other in collaborative mapping of current sectorial priorities and their linkages in order to identify vulnerabilities to global and local phosphorus challanges as well as potential intervientions.

Box 1. Stakeholder identification and diversity mapping.

\section{References:}

1. Chen M, Graedel T: A half-century of global phosphorus flows, stocks, production, consumption, recycling, and environmental impacts. Global Environmental Change 2016, 36: 139-152.

2. Schlesinger WH, Bernhardt ES: Biogeochemistry: An Analysis of Global Change,3rd ed., Academic Press,Waltham, Mass. 2014.

3. Bennett E, Carpenter S, Caraco N: Human impact on erodable phosphorus and eutrophication: a global perspective. BioScience 2001, 51: 227-234.

\author{
4. Smil V: Phosphorus In The Environment: Natural Flows and Human \\ Interferences. Annual review of energy and the environment 2000, 25:53-88.
}

5. Steffen W, Richardson K, Rockström J, Cornell SE, Fetzer I, Bennett EM, Biggs R, Carpenter SR, de Vries W, de Wit CA: Planetary boundaries: Guiding human development on a changing planet. Science 2015, 347:1259855.

6. MacDonald GK, Bennett EM, Potter PA, Ramankutty N: Agronomic phosphorus imbalances across the world's croplands. Proceedings of the National Academy of Sciences 2011, 108:3086-3091.

7. United Nations Environmental Programme: UNEP Year book: emerging Issues in our global environment 2011. Nairobi, Kenya. 
**8. Cordell D, White S: Life's Bottleneck: Sustaining the World's Phosphorus for a Food Secure Future. Annual Review of Environment \& Resources 2014, 39:168-188.

This paper provides an integrated synthesis of the biophysical, social, geopolitical, and institutional challenges and opportunities for sustaining phosphorus for a food secure future. The authors emphasize the role of governance to move toward phosphorus security.

9. Cordell D, Neset TS: Phosphorus vulnerability: A qualitative framework for assessing the vulnerability of national \& regional food systems to the multidimensional stressors of phosphorus scarcity. Global Environmental Change 2014, 24:108-122.

10. Carpenter S, Bennett E: Reconsideration of the planetary boundary for phosphorus. Env Research Letters 2011, 6:1-12.

11. Schindler D: Evolution of phosphorus limitation in lakes. Science 1977, 195:260262.

12. Carpenter S, Caraco NF, Correll DL, Howarth RW, Sharpley AN, Smith VH:

Nonpoint pollution of surface waters with phosphorus and nitrogen. Ecological Applications 1998, 8:559-568.

13. Smith V, Schindler D: Eutrophication science: where do we go from here? Trends in Ecology \& Evolution 2009, 24:201-207.

14. Anderson DM, Glibert PM, Burkholder JM: Harmful algal blooms and eutrophication: nutrient sources, composition, and consequences. Estuaries 2002, 25:704-726.

15. Diaz RJ, Rosenberg R: Introduction to Environmental and Economic Consequences of Hypoxia. Water Resources Development 2011, 27:71-82.

16. Rabalais NN, Turner RE, Diaz RJ, Justic D: Global change and eutrophication of coastal waters. ICES Journal of Marine Science: Journal du Conseil 2009, 66:15281537.

17. Grimm N, Faeth S, Golubiewski N, Redman C: Global change and the ecology of cities. Science 2008, 319:756-760.

18. Rosenzweig C: All Climate is Local. Scientific American 2011, 305:70-73.

19. Kennedy C, Pincetl S, Bunje P: The study of urban metabolism and its applications to urban planning and design. Environmental Pollution 2010, 159:19651973. 
**20. Metson GS, Iwaniec DM, Baker L, Bennett EM, Childers DL, Cordell D, Grimm NB, Grove JM, Nidzgorski D, White S: Urban phosphorus sustainability: Systemically incorporating social, ecological, and technological factors into phosphorus flow analysis. Environment Science \& Policy 2015, 47:1-11.

Based on a review of the urban phosphorus literature, the authors propose a framework to incorporate social-ecological-technological context to more holistically address phosphorus challenges. The framework includes 8 categories of factors that affect urban phosphorus stocks and flows: biogeophysical situation, infrastructure and land use, market and capital availability, knowledge and access to information, governance and actors, government and regulation, cultural norms and preferences, future priorities and plan.

21. Metson GS, Bennett EM: Phosphorus Cycling in Montreal's Food and Urban Agriculture Systems. PLoS ONE 2015, 10:e0120726-e0120726.

22. Childers D, Corman J, Edwards M, Elser J: Sustainability challenges of phosphorus and food: solutions from closing the human phosphorus cycle. Bioscience 2011, 61:117-124.

23. Childers, DL, Caple Z, Carlielle-Marquet C, Cordell D, Gerhart V, Iwaniec DM, White S: Future scenarios for the global sustainable use of P. In Phosphorus, Food, Our Futures. Edited by Elser J, Wyant K, Corman J. Oxford Press; 2013:183-198.

24. Pearce BJ: Phosphorus Recovery Transition Tool (PRTT): a transdisciplinary framework for implementing a regenerative urban phosphorus cycle. Journal of Cleaner Production 2015, 109:203-215.

25. Thapa YB: Constraints and approach for improving fertilizer supply for meeting domestic demand. Policy Paper Economic Policy, Government of Nepal/ Ministry of Finance Network Songha Durbar, Kathmandu, Nepal, 2006.

26. Tilley E, Gantenbein B, Khadka R, Zurbrugg C, Udert K: Social and economic feasibility of struvite recovery from Urine at the community level in Nepal. International Conference on Nutrient Recovery from Wastewater Streams. IWA Publishing, Vancouver, British Columbia, 2009 pp. 169-178.

27. Smith DR, King KW, Williams MR: What is causing the harmful algal blooms in Lake Erie? Journal of Soil and Water Conservation 2015, 70:27A-29A.

28. Brito L, Stafford-Smith M: State of the Planet Declaration. Planet Under Pressure: New Knowledge Towards Solutions conference. London; 2012. Available at: http://www.planetunderpressure2012.net/pdf/state_of_planet_declaration.pdf.

29. Ehrlich P, Ehrlich A: Can a collapse of global civilization be avoided? Proceedings of the Royal Society of London B: Biological Sciences 2013, 280:20122845-2012284. 
30. Elser J, Bennett E: Phosphorus cycle: A broken biogeochemical cycle. Nature 2011, 478:29-31.

31. Suh S, Yee S: Phosphorus use-efficiency of agriculture and food system in the US. Chemosphere 2011, 84:806-813.

32. Senthilkumar K, Mollier A, Delmas M, Pellerin S, Nesme T: Phosphorus recovery and recycling from waste: An appraisal based on a French case study. Resources, Conservation and Recycling 2014, 87:97-108.

33. Cordell D, Rosemarin A, Schroder J, Smit A: Towards global phosphorus security: a systems framework for phosphorus recovery and reuse options. Chemosphere $2011,84: 747-758$.

34. Kalmykova Y, Harder R, Borgestedt H, Svanang I: Pathways and management of phosphorus in urban areas. Journal of Industrial Ecology 2012, 16:928-939.

35. Gumbo B, Savenije H, Kelderman P: Ecologising societal metabolism: The case of phosphorus. Proc 3rd Int Conf Environmental Management 2002:27-30.

36. Leitzinger C: The protential of co-comporting in Kumasi - Quantification of the urban and peri-urban balance. In Waste composting for urban and peri-urban agriculture: Closing the rural-urban nutrient cycle in sub-Saharan Africa. Edited by Drechsel P, Kunze D: CABI; 2001:150-162.

37. Montangero A, Cau LN, Anh NV, Tuan VD, Nga PT, Belevi H: Optimising water and phosphorus management in the urban environmental sanitation system of Hanoi, Vietnam. Science of The Total Environment 2007, 384:55-66.

38. Neset T-SS, Bader H-P, Scheidegger R, Lohm U: The flow of phosphorus in food production and consumption - Linköping, Sweden,1870-2000 Science of the Total Environment 2008, 396:111-120.

39. MacDonald GK, Bennett EM, Carpenter SR: Embodied phosphorus and the global connections of United States agriculture. Environmental Research Letters 2012, 7:044024.

*40. Jarvie HP, Sharpley AN, Flaten D, Kleinman PJ, Jenkins A, Simmons T: The pivotal role of phosphorus in a resilient water-energy-food security nexus. Journal of Environmental Quality 2015, 44:1049-1062.

The US agricultural system is used as an example to describe how phosphorus in inextricable tied to water quality, energy through biofuel production, and food security. The authors demonstrate how past practices have created inequalities that threaten these three inter-related priorities, but that sustainable phosphorus opportunities are emerging. 
41. Neset TSS, Cordell D: Global phosphorus scarcity: identifying synergies for a sustainable future. Journal of the Science of Food and Agriculture 2012, 92:2-6.

42. Tangsubkul N, Moore S, Waite TD: Incorporating phosphorus management considerations into wastewater management practice. Environmental Science \& Policy 2005, 8:1-15.

*43. Lang DJ, Wiek A, Bergmann M, Stauffacher M, Martens P, Moll P, Swilling M, Thomas CJ: Transdisciplinary research in sustainability science: practice, principles, and challenges. Sustainability Science 2012, 7:25-43.

This provides a review on co-production and transdisciplinary research literature and synthesizes it into a proposed "state of the art" transdisciplinary research framework.

44. Iwaniec DM, Childers D, VanLehn K, Wiek A: Studying, Teaching \& Applying Sustainability Visions Using Systems Modeling. Sustainability 2014, 6:4452-4469.

**45. Mitchell C, Cordell D, Fam D: Beginning at the end: The outcome spaces framework to guide purposive transdisciplinary research. Futures 2015, 65:86-96.

This paper articulates how in transdiciplinary reserach creating a clear and shared picuture of the desired outcomes of a project is key to success. They put forth three distinct but overlaping types of outcomes that should be mapped at the onset of a project: Situation (which refers to the topic area under study), Knowledge (which refers to both scholarly and public outputs to share insights), and Learning (which refers to the lasting change in the way reserach participants examine the issue).

46. Hackmann H, Moser S, St Clair A: The social heart of global environmental change. Nature Climate Change 2014, 4:653-655.

47. Midgley G: Science as Systemic Intervention: Some Implications of Systems Thinking \& Complexity for the Philosophy of Science. Systemic Practice \& Action Research 2003, 16:77-97.

48. Moore M-L, Tjornbo O, Enfors E, Knapp C, Hodbod J, Baggio JA, Norström A, Olsson P, Biggs D: Studying the complexity of change: toward an analytical framework for understanding deliberate social-ecological transformations. Ecology \& Society 2014, 19:1-10.

49. Brandt P, Ernst A, Gralla F, Luederitz C, Lang DJ, Newig J, Reinert F, Abson DJ, von Wehrden $\mathrm{H}$ : A review of transdisciplinary research in sustainability science. Ecological Economics 2013, 92:1-15. 
50. Pahl-Wostl C: A conceptual framework for analysing adaptive capacity \& multilevel learning processes in resource governance regimes. Global Environmental Change 2009, 19:354-365.

51. Jacobs B, Lee C, O'Toole D: Integrated regional vulnerability assessment of government services to climate change. International Journal of Climate Change Strategies \& Management 2014, 6:272-295.

52. Leach M, Scoones I, Stirling A: Dynamic Sustainabilities: Technology, Environment, Social Justice. Earthscan; 2010.

*53. Wiek A, Iwaniec DM: Quality criteria for visions and visioning in sustainability science. Sustainability Science 2014, 9:497-512.

This paper synthesizes the diverse literature on visioning to develop a framework to craft and analyze sustainability visions. The framework consists of quality criteria for sustainability visioning, and derives design principles for participatory research from the quality criteria.

54. Iwaniec DM, and Wiek A: Advancing Sustainability Visioning Practice in Planning - the General Plan Update in Phoenix, Arizona. Planning Practice and Research 2014, 29:543-568.

55. Loorbach D, Rotmans J: Managing Transitions for Sustainable Development. In Understanding Industrial Transformation. Editted by Olsthoorn X, Wieczorek AJ. Springer Netherlands; 2006:187-206.

56. Rotmans J, Loorbach D: Complexity and Transition Management. Journal of Industrial Ecology 2009, 13:184-196.

57. Cordell D, Mikhailovich N, Mohr S, Jacobs B, White S: Australian sustainable phosphorus futures Phase II: Adapting to future phosphorus scarcity: investigating potential sustainable phosphorus measures and strategies, RIRDC Publication No. 14/039 RIRDC, 2014: Project No. PRJ-008789. 


\begin{tabular}{|l|l|}
\hline Sector & Relevance \\
\hline City planning & $\begin{array}{l}\text { government perspective of city and regional priorities and goals; } \\
\text { implementation of future options }\end{array}$ \\
\hline $\begin{array}{l}\text { Food production, } \\
\text { distribution, and } \\
\text { consumption }\end{array}$ & $\begin{array}{l}\text { upstream source of } \mathrm{P} \text { (e.g., urban farmers, food retailers) and } \\
\text { potions for recycling and efficiency (e.g., reducing waste) }\end{array}$ \\
\hline $\begin{array}{l}\text { Fertilizer production, } \\
\text { distribution, and advising }\end{array}$ & upstream sources of P for food and landscaping \\
\hline $\begin{array}{l}\text { Solid waste } \\
\text { management (organic) }\end{array}$ & downstream flows of P and capacity for recycling \\
\hline $\begin{array}{l}\text { Wastewater and sewage } \\
\text { sanitation services }\end{array}$ & downstream flows of P and capacity for recycling \\
\hline Water management & recycling through water reuse \\
\hline $\begin{array}{l}\text { Land-use decision- } \\
\text { making }\end{array}$ & land use changes affect our ability to recycle P \\
\hline Marginalized groups & $\begin{array}{l}\text { stakeholders that are influenced by decision-making but may have } \\
\text { limited capacity to implement changes (e.g., those living on the city } \\
\text { fringes in underserviced areas) }\end{array}$ \\
\hline $\begin{array}{l}\text { Public health and } \\
\text { consumer advocacy }\end{array}$ & $\begin{array}{l}\text { access to healthy foods, clean water and air; environmental and } \\
\text { social justice }\end{array}$ \\
\hline Environmental protection & $\begin{array}{l}\text { terrestrial and aquatic ecosystem health threatened by nutrient } \\
\text { pollution }\end{array}$ \\
\hline Non-food vegetation & management of timber and municipal landscaping \\
\hline Non-food P industry & $\begin{array}{l}\text { industries that use } P \text { as an input in high-tech processing (e.g., } \\
\text { detergents, flame retardants, paints, adhesives, pet food, and other } \\
\text { industries) }\end{array}$ \\
\hline
\end{tabular}

\section{Types of Stakeholder Groups:}

Government (e.g., representatives for city, state, and regional governance)

Non-profits (e.g., community and advocacy organizations)

Industry (e.g., industry associations)

Individual actors (e.g., farmers, community members)

Marginalized stakeholders (e.g., community leaders and advocacy organizations for marginalized stakeholders-including consumer groups)

Researchers (i.e., social, natural, engineering, and humanities scholars 


\section{Challenges}

- $P$ accessibility

- P pollution

- Lack of governance

\section{P-FUTURES Approach}

Figure 1

Diverse partner cities:

Hanoi, Vietnam

Blantyre, Malawi

Sydney, Australia

$\square$ Phoenix, USA

Stakeholder diversity \& identification (see Box 1)

Experiential learning \& field visits

Diverse stakeholders \& cities learning from one another

Articulated desirable future scenarios \& plausible pathways

Broader dissemination \& greater awareness of food \& water sustainability

Changes in stakeholder behaviour \& practice
Interactive workshops

\& group learning:

- Mapping current state \& goals

- $P$ vulnerability assessment

- Urban P visions

- Adaptive strategies \& pathways

- Project co-development

\section{Seed Phase Outcomes}

Build capacity for social transformation

Diverse stakeholders within a city learning from one another

Explore local vulnerabilities and desirable visions \& pathways

Web-platform for public dissemination \& partner sharing

Co-development of full proposal \& transdisciplinary approach 


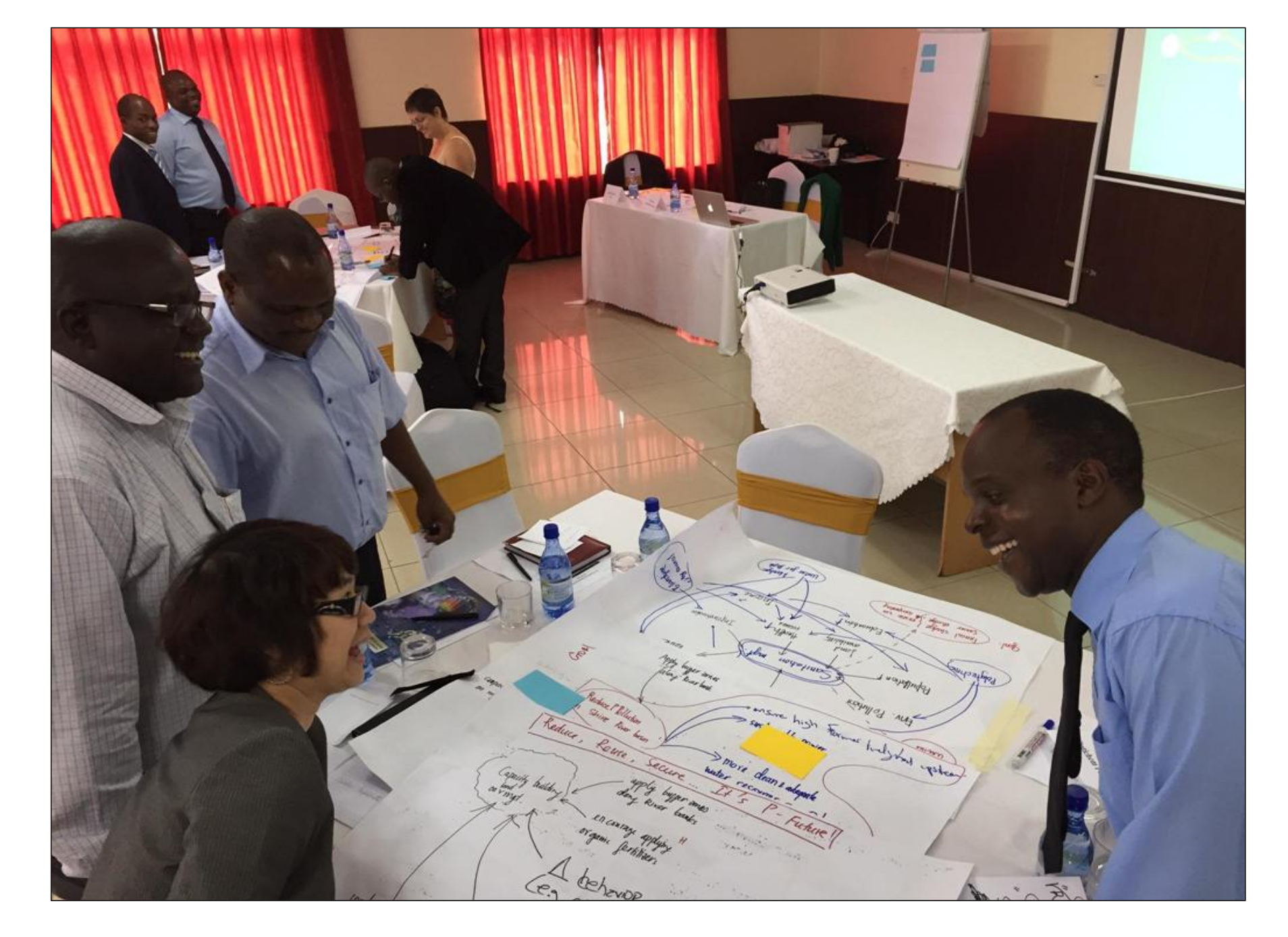

Figure 2

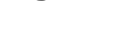

\section{列}
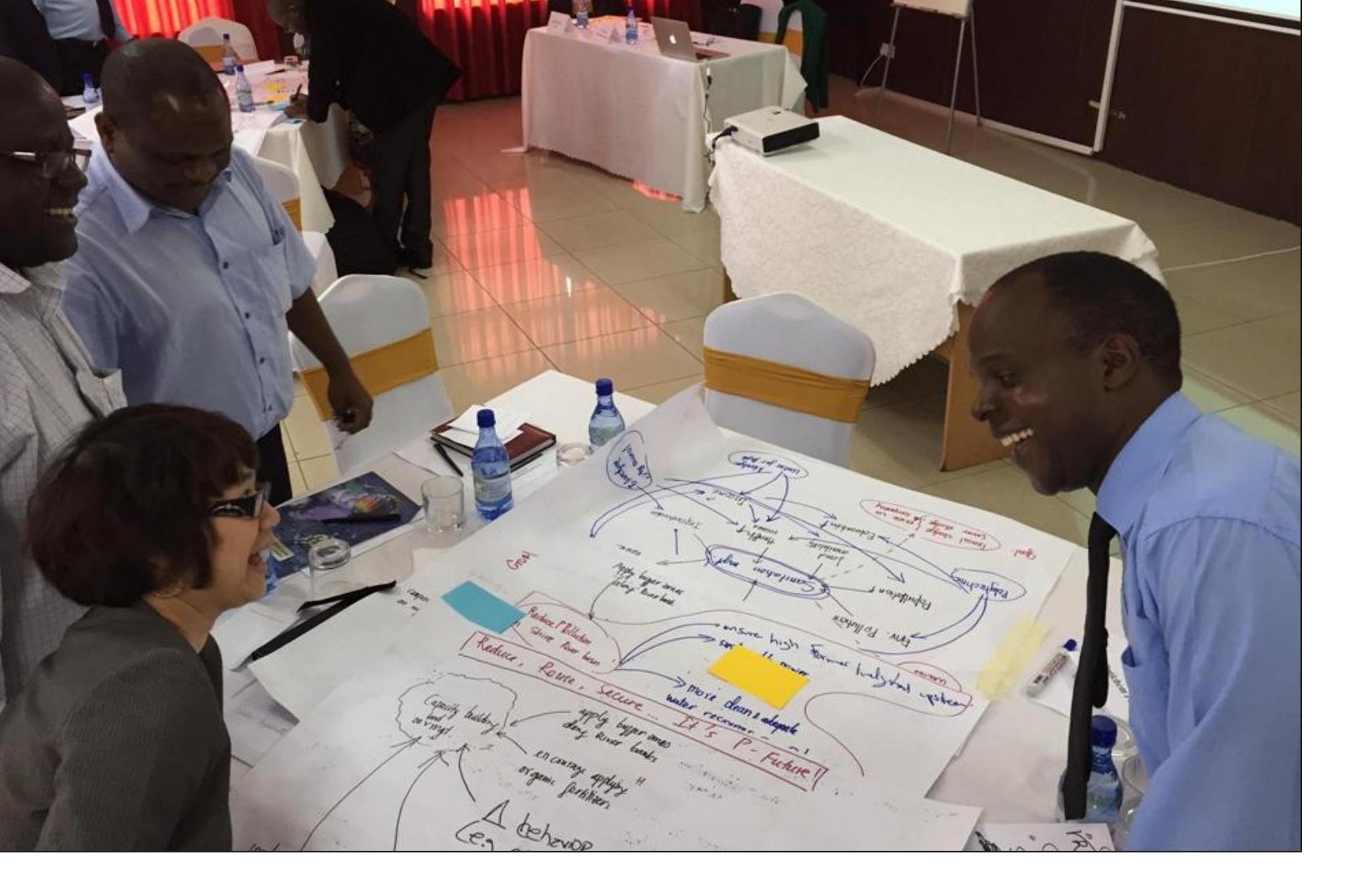

.

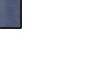

